\title{
ケーブルを有した機械システムの運動解析および制御に関する研究
}

\author{
山本 武志 ${ }^{* 1}$ ，菅原 佳城*2，坂間 清子*2
}

\section{A study on motion analysis and control of mechanical systems connected by a cable}

\author{
Takeshi YAMAMOTO*1, Yoshiki SUGAWARA*2 and Sayako SAKAMA*2 \\ ${ }^{* 1}$ Graduate School of Science and Engineering, Aoyama Gakuin University \\ 5-10-1 Fuchinobe, Chuo-ku, Sagamihara-shi, Kanagawa 252-5258, Japan \\ ${ }^{* 2}$ College of Science and Engineering, Aoyama Gakuin University \\ 5-10-1 Fuchinobe, Chuo-ku, Sagamihara-shi, Kanagawa 252-5258, Japan
}

Received: 15 November 2018; Revised: 22 February 2019; Accepted: 27 June 2019

\begin{abstract}
Cables connected to mechanical systems enable efficiently power supply to the system and also enable high speed communication even in a poor communication environment. But it is not easy to control position and attitude of such mechanical systems with cables or tethers, because tension and inertia of the cables become disturbances, which greatly affect the behavior of the mechanical system. However, there is not enough studies on the control of such a mechanical system with cable. In this study, the cable is expressed by absolute nodal coordinate formulation (ANCF) which is one of the nonlinear finite element methods. The control system design method using the ANCF model has not been established and there are few research examples. Control law is derived by the use of the special feature of obtained model, that is inertia matrix of the system is constant. By applying coordinate transformation utilizing the feature, a controller design problem for mechanical system with cable is converted to that for mechanical system which consists of only rigid body, and the derive controller achieves low calculation cost. The proposed method controls the mechanical system so that the influence of the tether is compensated. Furthermore, in order to achieve the proposed control law, state variables of the cable are estimated by Kalman filter. Numerical analyses are carried out for evaluation of the proposed method.
\end{abstract}

Keywords : Absolute nodal coordinate formulation, Cable, Flexible multibody system, Motion control, State estimation, Unscented Kalman Filter

\section{1. 緒言}

ケーブルを有した機械システムの例として，建造物などの点検用の小型ヘリコプタ（田所，2014）や海中探査 用ロボット(浦, 2004)が挙げられる. 近年, 高度成長期に建設された高速道路や橋梁の老朽化が進んでおり, 建築 物の検査・メンテナンスが急務である．従来の検査では，足場や大型クレーンを用いて人手による目視検査や打 音検查を行なうことが多いが，足場の建設や大型クレーンの出動にコストや検査時間が必要である．そのため， 詳細な検査が必要な建築物を抽出するための予備検査を低コストかつ短時間で行うことができる簡易的な検査方 法が求められている，その方法の一つとして，カメラを搭載した小型ヘリコプタを利用した目視検查が挙げられ る. 小型ヘリコプタを用いた目視検査も近年普及してきたが，バッテリーを搭載したものでは飛行時間が短く， 目視検査をするには不十分である，その対策として，電源容量のある地上から小型へリコプタにケーブルをつな いで給電することで，飛行時間の問題を解消できる．さらに，カメラ画像などの大容量データを有線で確実に取 得でき，地上の高性能コンピュータを用いてリアルタイムで解析できるようになる．また，一般的にロボットの 遠隔操作を円滑に行うには，通信および位置情報が必要である，一方，海中での無線通信には音響通信が用いら

No.18-00455 [DOI:10.1299/transjsme.18-00455], J-STAGE Advance Publication date : 8 July, 2019

本論文は，Dynamics and Design Conference 2018 講演論文集(2018), No.706の掲載内容に基づいた論文である.

*1 学生員, 青山学院大学大学院 理工学研究科（广252-5258 神奈川県相模原市中央区淵野辺 5-10-1）

*2 正員, 青山学院大学 理工学部

E-mail of corresponding author: sugawara@me.aoyama.ac.jp 
れるが，音波の伝播速度は遅く，さらに伝送密度も小さいことから海中でのロボットの遠隔操縦のための通信手 段として用いることは困難であり，陸上におけるロボットのようなリアルタイムの遠隔操縦は不可能である. し たがって, ロボットにケーブルを取り付けて海上の操縦システムと接続することで, 海中のような通信状況の悪 い条件であってもロボットからのリアルタイムの情報の確保と操縦を可能とする.

このように，ケーブルを有した機械システムでは，電力供給や通信を効率よく行うことができ，通信障害を受 けや寸い場所でも運用可能となる一方で，ケーブルの張力や慣性が外乱となり，機械システムの位置や姿勢の制 御に悪影響を与える可能性があるといった問題がある. そこでケーブルが機械システムの位置や姿勢の制御に与 える影響を解析し, その影響を補正するような制御系の設計を行うことで, ケーブルを有した機械システムの様々 な分野への適用範囲が拡大寸ることが期待される.

既往の研究では, ケーブルを有した機械システムの張力補償制御に関する研究(今津他，2014)や最適なケーブ ルの長さに関する研究(今津他, 2016)やケーブルのみの動的マニピュレーションに関する研究(山川他, 2013)が行 われているが，ケーブルを有した機械システムの運動制御に関する研究は不十分である．機械システムの運動制 御における制御系設計のためには，一般的に対象の数学モデルの定式化が要求されることが多い. このとき，ケ 一ブルを有した機械システムが様々な運動を行う際にはケーブルは様々な形状になる可能性があり，そのような 機械システムの運動制御のために微小な変形から大きな変形まで表現できる定式化手法が求められる. そこで本 研究では, Shabana らによって提案された非線形有限要素法の一種である絶対節点座標法 (Absolute Nodal Coordinate Formulation: ANCF）(Shabana et al., 1998)を用いてケーブルを有した機械システムの数学モデルの導出を 行い，さらに得られた数学モデルを用いることで，ケーブルの先端に接続された機械システムの位置および姿勢 に関する制御系設計を行うことを研究目的とする。ここで，ケーブルが弛まないような状態での運用は対象とす るシステムの作業領域の境界となり，実用性かつ安全性の観点からそのような運用は避けることが一般的である と考えられる. そのため, 本研究ではケーブルが驰んだ状態における制御に着目することに注意されたい. また, ANCF によって得られた数学モデルを用いた制御系設計手法についての研究はまだ不十分(菅原, 小林, 2012)であ り，その制御系設計への活用手法も重要な検討事項である. 提案手法では得られた数学モデルの特性を利用する ことで，先端に接続された機械システムの運動へのケーブルの影響を補償する効果を有する制御則を導出し，制 御則に必要となるケーブルの状態变数はカルマンフィルタで推定を行う. また, 提案手法については数值解析に よってその妥当性の検証を行う。

本論文の構成は以下の通りである. 2 章では制御対象を示し, その運動方程式を導出する. 3 章では 2 章で導出 した運動方程式を用いた制御系設計手法の提案を行う. 4 章では提案する制御系に必要となる状態推定について 述べる. 5 章では提案する制御系の有効性を数值解析により確認する. 6 章ではまとめと今後の課題を示す.

\section{2. 制御対象とモデル化}

\section{$2 \cdot 1$ 制御対象}

図 1 に解析対象のモデルを示寸，モデルはケーブルと剛体で構成される. ケーブルの片端は地面にピン支持に より接続され，もう一方は剛体にピン支持により接続されている. また, ケーブルの断面および密度は一様で, 空気抵抗はないものとし, 鉛直下向き（-Y 方向）に重力加速度が加わるものとする．剛体は正方形形状であり 密度は一様であるとし, 鉛直下向き（-Y方向）に重力加速度が加わり， $x, y$ および $\theta$ 方向にそれぞれ制御入力 $F_{x}, F_{y}$ および $\tau_{\theta}$ を印加できるものとする.

\section{$2 \cdot 2$ 数学モデルの導出}

ケーブルのような柔軟な構造物には大変形を考慮した定式化が必要である. ANCF は節点の座標や勾配を絶対 座標で表すことで大变形や大回転を含む動的解析を少ない要素数で高精度に行うことが可能であり, 慣性項が線 形になる一方，岡性項が強い非線形性を示すという特徵を持つ. ANCF を用いてケーブルを表現するために図 2 のように，ケーブルを $N$ 個の要素に分割する. 要素長さが $l$ である $j$ 番目の要素上の任意点 $\mathrm{P}_{j}$ における任意の位 置ベクトル $\mathbf{r}_{j}$ は, 形状関数行列 $\mathbf{S}_{j}$ および節点座標ベクトル $\mathbf{e}_{j}$ を用いて式(1)のように表される. 


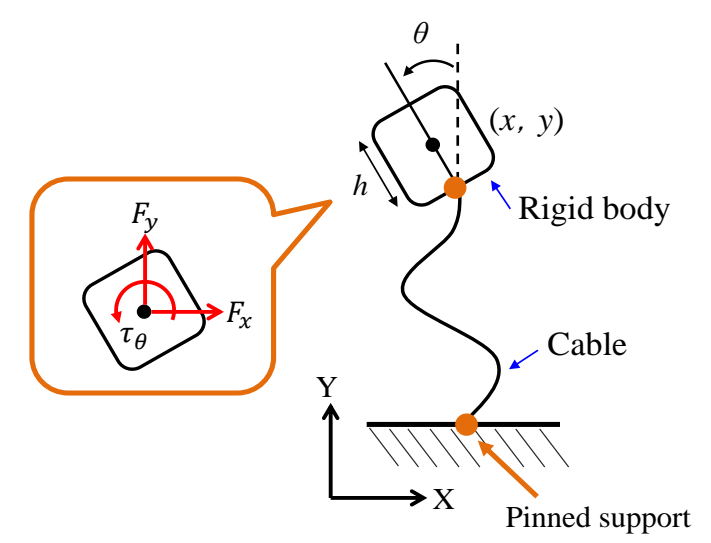

Fig. 1 The model consists of cable and rigid body, one end of the cable is connected to the ground by pin support, and the other is connected to the rigid body by pin support.

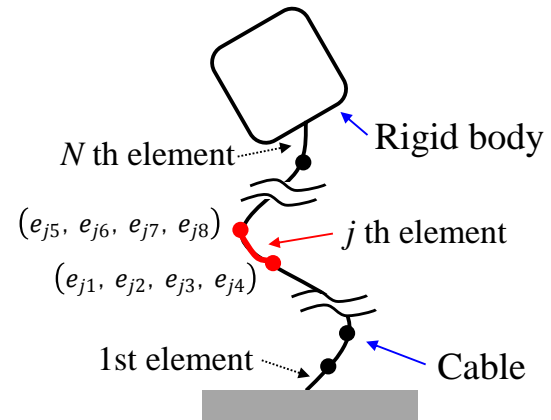

Representation of cable by $N$ elements

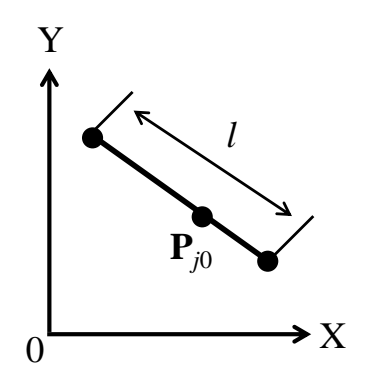

Before deformation of $j$ th element

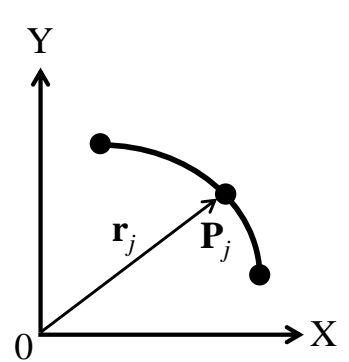

After deformation of $j$ th element

Fig. 2 The cable is divided into $N$ elements, and as a representative example, the $j$-th elements before and after deformation are shown.

$$
\mathbf{r}_{j}\left(x_{j}\right)=\left[\begin{array}{l}
r_{j X}\left(x_{j}\right) \\
r_{j Y}\left(x_{j}\right)
\end{array}\right]=\mathbf{S}_{j}\left(x_{j}\right) \mathbf{q}_{c j}
$$

ここで, $x_{j}$ は第 $j$ 要素の無変形時の要素上の点の位置を表す局所座標であり, ケーブルの第 $j$ 要素の節点座標ベク トル $\mathbf{q}_{c j}$ は式(2)のように表される。

$$
\mathbf{q}_{c j}=\left[\begin{array}{llllllll}
e_{j 1} & e_{j 2} & e_{j 3} & e_{j 4} & e_{j 5} & e_{j 6} & e_{j 7} & e_{j 8}
\end{array}\right]^{\mathrm{T}}
$$

ただし $, e_{j 1}, e_{j 2}, e_{j 5}, e_{j 6}$ は第 $j$ 要素の両端の節点の絶対座標を表す要素であり, $e_{j 1}$ および $e_{j 2}$ は一端のXおよび $\mathrm{Y}$ 座標であり， $e_{j 5}$ および $e_{j 6}$ は他端の Xおよび Y 座標である. $e_{j 3}, e_{j 4}, e_{j 7}, e_{j 8}$ は第 $j$ 要素の両端の節点の絶対座標の 局所座標 $x_{j}$ に対する勾配を表し, $e_{j 3}=\partial e_{j 1} / \partial x_{j}, e_{j 4}=\partial e_{j 2} / \partial x_{j}, e_{j 7}=\partial e_{j 5} / \partial x_{j}, \quad e_{j 8}=\partial e_{j 6} / \partial x_{j}$ あ゙る. ここ で, 運動エネルギ $T$, 軸変形に関する歪みエネルギ $U_{1}$, 曲げ変形に関する歪みエネルギ $U_{\mathrm{t}}$ はそれぞれ次のように 与えられる。

$$
\begin{gathered}
T=\frac{1}{2} \int_{0}^{l} \rho A \dot{\boldsymbol{r}}_{j}^{T} \dot{\boldsymbol{r}}_{j} d x_{j} \\
U_{\mathrm{l}}=\frac{1}{2} \int_{0}^{l} E A \varepsilon_{l j}^{2} d x_{j} \\
U_{\mathrm{t}}=\frac{1}{2} \int_{0}^{l} E I \kappa_{j}^{2} d x_{j}
\end{gathered}
$$


ただし， $\rho$ はケーブルの密度，Aはケーブルの断面積， $E$ はケーブルのヤング率， $\varepsilon_{l j}$ は第 $j$ 要素の軸歪み, $I$ はケー ブルの断面二次モーメント， $\kappa_{j}$ は第 $j$ 要素の曲率である.このとき, 式(3)における $\dot{\boldsymbol{r}}_{j}$, 式(4)における $\varepsilon_{l j}$ および式 (5)における $\kappa_{j}$ のそれぞれを式(1)を用いて表現した各エネルギと外力による仮想仕事を用いてラグランジュ方程 式を導出すると, ケーブルの第 $j$ 要素の運動方程式が式(6)のように得られる. ここで, 軸歪み $\varepsilon_{l j}$ および曲率 $\kappa_{j}$ の 式(1)を用いた表現の詳細については参考文献(Berzeri and Shabana, 2000)を参照されたい.

$$
\mathbf{M}_{c j} \ddot{\mathbf{q}}_{c j}+\mathbf{K}_{\mathbf{l j}} \mathbf{q}_{c j}+\mathbf{K}_{\mathbf{t} j} \mathbf{q}_{c j}=\mathbf{Q}_{E c j}
$$

ただし, $\mathbf{M}_{c j}$ は第 $j$ 要素の慣性行列， $\mathbf{K}_{\mathrm{l} j}$ は第 $j$ 要素の軸方向の伸びである軸変形に関する剛性行列， $\mathbf{K}_{\mathrm{t} j}$ は第 $j$ 要素 の曲げ変形に関する剛性行列および $\mathbf{Q}_{E c j}$ は第 $j$ 要素の重力等を含む外力ベクトルである．また，軸変形および曲 げ変形に関する剛性項は Berzeri らによって提案されている(Berzeri and Shabana, 2000). 曲げ岡性行列に関して軸 ひずみが小さい場合を仮定した $\mathrm{T} 1$ モデル，軸ひずみが大きい場合にも適用可能である $\mathrm{T} 2$ モデルの 2 種類があ る.また，軸剛性行列に関して要素内の軸ひずみが一定であると仮定した L1 モデル，より一般的なひずみ状態 を取り扱える L2 モデル，L2 モデルを簡略化しひずみが小さい場合を仮定した L 3 モデルの 3 種類がある. これ ら 5 つのモデルのうち, $\mathrm{T} 1$ モデルのみ剛性行列 $\mathbf{K}_{\mathrm{j} j}$ が一定值になる特徴を有しており, それ以外のモデルは節点 座標の関数であるため強い非線形性を有する剛性項となる. 本研究では準備的な解析により計算負荷および精度 を考慮して T1 および L2 モデルを採用しており, その結果として $\mathbf{K}_{\mathrm{lj}}$ は定数行列, $\mathbf{K}_{\mathbf{t} j}$ は一般化座標 $\mathbf{q}_{c j}$ に依存し た行列となっている. ここで, 各要素の運動方程式を一組にまとめることで, ケーブルに関する運動方程式を次 のように導出することができる.

$$
\mathbf{M}_{c} \ddot{\mathbf{q}}_{c}+\mathbf{K}_{\mathbf{l}} \mathbf{q}_{c}+\mathbf{K}_{\mathbf{t}} \mathbf{q}_{c}=\mathbf{Q}_{E c}
$$

ここで $\mathbf{q}_{c}$ はケーブルの一般化座標ベクトルであり式(8)のように表される.

$$
\mathbf{q}_{c}=\left[\begin{array}{lllll}
\mathbf{q}_{c 1}{ }^{\mathrm{T}} & \cdots & \mathbf{q}_{c j}{ }^{\mathrm{T}} & \cdots & \mathbf{q}_{c N}{ }^{\mathrm{T}}
\end{array}\right]^{\mathrm{T}}
$$

また, 慣性行列 $\mathbf{M}_{c}$, 曲げ変形に関する岡性行列 $\mathbf{K}_{\mathbf{t}}$, 軸変形に関する剛性行列 $\mathbf{K}_{\mathbf{l}}$ および外力ベクトル $\mathbf{Q}_{E c}$ はそれ ぞれ式(9), 式(10), 式(11)および式(12)のように表される.

$$
\begin{aligned}
& \mathbf{M}_{c}=\operatorname{blockdiag}\left(\mathbf{M}_{c 1}, \cdots, \mathbf{M}_{c j}, \cdots, \mathbf{M}_{c N}\right) \\
& \mathbf{K}_{\mathbf{l}}=\operatorname{blockdiag}\left(\mathbf{K}_{\mathbf{l} 1}, \cdots, \mathbf{K}_{\mathbf{l j}}, \cdots, \mathbf{K}_{\mathbf{l N}}\right) \\
& \mathbf{K}_{\mathbf{t}}=\operatorname{blockdiag}\left(\mathbf{K}_{\mathbf{t} 1}, \cdots, \mathbf{K}_{\mathbf{t} j}, \cdots, \mathbf{K}_{\mathbf{t N}}\right) \\
& \mathbf{Q}_{E c}=\left[\begin{array}{lllll}
\mathbf{Q}_{E c 1}{ }^{\mathrm{T}} & \cdots & \mathbf{Q}_{E c j}{ }^{\mathrm{T}} & \cdots & \mathbf{Q}_{E c N}{ }^{\mathrm{T}}
\end{array}\right]^{\mathrm{T}}
\end{aligned}
$$

ただし, 本研究ではケーブルに加わる外力は重力のみであり, 式(12)の各要素は重力に起因したものである.

次に剛体の一般化座標 $\mathbf{q} r$ を式(13)のように示寸.

$$
\mathbf{q}_{r}=\left[\begin{array}{lll}
x & y & \theta
\end{array}\right]^{\mathrm{T}}
$$

このとき，剛体の運動方程式は式(14)のようになる.

$$
\mathbf{M}_{r} \ddot{\mathbf{q}}_{r}=\mathbf{Q}_{r}+\mathbf{Q}_{\mathrm{u}}
$$

ただし， $\mathbf{M}_{r}$ は慣性行列， $\mathbf{Q}_{r}$ は剛体に関する外力ベクトルおよび $\mathbf{Q}_{u}$ は制御入力ベクトルであり，本研究では剛体 に加わる外力は重力のみであることから $\mathbf{Q}_{r}$ および $\mathbf{Q}_{u}$ は以下のように与えられる.

$$
\begin{aligned}
\mathbf{Q}_{r} & =\left[\begin{array}{lll}
0 & -m g & 0
\end{array}\right]^{\mathrm{T}} \\
\mathbf{Q}_{u} & =\left[\begin{array}{lll}
F_{x} & F_{y} & \tau_{\theta}
\end{array}\right]^{\mathrm{T}}
\end{aligned}
$$

ここで，一般化座標ベクトル $\mathbf{q}$ を次のように定義する. 


$$
\mathbf{q}=\left[\begin{array}{ll}
\mathbf{q}_{c}{ }^{\mathrm{T}} & \mathbf{q}_{r}^{\mathrm{T}}
\end{array}\right]^{\mathrm{T}}
$$

このとき，ケーブルと地面の接続，ケーブルの各要素間の接続およびケーブルと剛体の接続に関する拘束方程式 $\mathbf{C}(\mathbf{q})=\mathbf{0}$ を求め, その拘束方程式に対して一般化座標ベクトル $\mathbf{q}$ 関する 2 階微分を施すことで加速度に関する 方程式を導出する.さらに，ラグランジュの未定乗数ベクトルれを導入することで加速度に関する方程式と式(7) および式(14)を随伴させた形として式(18)のような微分代数方程式（DAE）が導出される.

$$
\left[\begin{array}{cc}
\mathbf{M} & \mathbf{C}_{\mathbf{q}}^{\mathrm{T}} \\
\mathbf{C}_{\mathbf{q}} & \mathbf{0}
\end{array}\right]\left[\begin{array}{l}
\ddot{\mathbf{q}} \\
\lambda
\end{array}\right]=\left[\begin{array}{l}
\mathbf{Q} \\
\boldsymbol{\gamma}
\end{array}\right]
$$

ここで， $\mathbf{C}_{\mathbf{q}}$ はヤコビアンであり $\mathbf{C}_{\mathbf{q}}=\partial \mathbf{C}(\mathbf{q}) / \partial \mathbf{q}$ である. また, $\gamma$ は加速度に関する方程式を構成する項であり $\boldsymbol{\gamma}=-\left(\mathbf{C}_{\mathbf{q}} \dot{\mathbf{q}}\right)_{\mathbf{q}} \dot{\mathbf{q}}$ である. また, システム全体の慣性行列 $\mathbf{M}$ および一般化外力ベクトル $\mathbf{Q}$ は以下の通りである.

$$
\begin{aligned}
& \mathbf{M}=\left[\begin{array}{cc}
\mathbf{M}_{c} & \mathbf{0} \\
\mathbf{0} & \mathbf{M}_{r}
\end{array}\right] \\
& \mathbf{Q}=\left[\begin{array}{ll}
\mathbf{Q}_{c}{ }^{\mathrm{T}} & \mathbf{Q}_{r}{ }^{\mathrm{T}}+\mathbf{Q}_{u}{ }^{\mathrm{T}}
\end{array}\right]^{\mathrm{T}}
\end{aligned}
$$

さらに， $\mathbf{Q}_{c}$ はケーブルに関するカベクトルであり，式(21)のように与えられる.

$$
\mathbf{Q}_{c}=\mathbf{Q}_{E c}-\left(\mathbf{K}_{t}+\mathbf{K}_{l}\right) \mathbf{q}_{c}
$$

式(18)の DAE を汎用的な制御系設計によく用いられる状態方程式に変換するためにニュートン・オイラー方程 式の導出を行う. 一般化座標ベクトル $\mathbf{q}$ の要素に関して独立な座標変数を並べたベクトルを $\mathbf{q}_{i n}$, 従属な座標变数 を並べたベクトルを $\mathbf{q}_{d p}$ とする. ここで，剛体に関する一般化座標ベクトルの 3 成分，ケーブルの根元要素の勾 配およびケーブルの第 2 要素以降の第 $i$ 要素における第 $i-1$ 要素の側に接続される節点座標を独立な座標変数と しており, それ以外の座標変数を従属な座標変数としている. このとき， $\mathbf{q}_{i n}$ と $\mathbf{q}_{d p}$ を並べたべクトルを $\overline{\mathbf{q}}$ とする と， q と市の関係は式(22)のようになる.

$$
\mathbf{q}=\mathbf{T}_{i d}\left[\begin{array}{c}
\mathbf{q}_{i n} \\
\mathbf{q}_{d p}
\end{array}\right]=\mathbf{T}_{i d} \overline{\mathbf{q}}
$$

ただし， $\mathbf{T}_{i d}$ は一般化座標ベクトル $\mathbf{q}$ を独立な座標変数と従属な座標変数に並び替える座標変換行列である．こ のとき以下の行列を導入する.

$$
\begin{aligned}
& \mathbf{T}_{i d}{ }^{\mathrm{T}} \mathbf{M} \mathbf{T}_{i d}=\left[\begin{array}{ll}
\mathbf{M}_{i n} & \mathbf{M}_{i d} \\
\mathbf{M}_{d i} & \mathbf{M}_{d p}
\end{array}\right]=\overline{\mathbf{M}} \\
& \mathbf{C}_{\mathbf{q}} \mathbf{T}_{i d}=\left[\begin{array}{ll}
\mathbf{C}_{\mathbf{q} i n} & \mathbf{C}_{\mathbf{q} d p}
\end{array}\right] \equiv \overline{\mathbf{C}}_{\mathbf{q}} \\
& \mathbf{T}_{i d}{ }^{\mathrm{T}} \mathbf{Q}=\left[\begin{array}{ll}
\mathbf{Q}_{i n}{ }^{\mathrm{T}} & \mathbf{Q}_{d p}{ }^{\mathrm{T}}
\end{array}\right] \equiv \overline{\mathbf{Q}}
\end{aligned}
$$

ここで, 下付き添字 in は独立な座標変数に関する成分を表し, 下付き添字 $d p$ は従属な座標変数に関する成分を 表し，下付き添字 $i d$ および $d i$ は独立な座標変数および従属な座標変数の連成に関する成分を表す．このとき， 式(23)，式(24)，式(25)を用いると式(18)は式(26)のように表される.

$$
\left\{\begin{array}{c}
\mathbf{M}_{i n} \ddot{\mathbf{q}}_{i n}+\mathbf{M}_{i d} \ddot{\mathbf{q}}_{d p}+\mathbf{C}_{\mathbf{q} i n}{ }^{\mathrm{T}} \boldsymbol{\lambda}-\mathbf{Q}_{i n}=\mathbf{0} \\
\mathbf{M}_{d i} \ddot{\mathbf{q}}_{i n}+\mathbf{M}_{d p} \ddot{\mathbf{q}}_{d p}+\mathbf{C}_{\mathbf{q} d p}{ }^{\mathrm{T}} \boldsymbol{\lambda}-\mathbf{Q}_{d p}=\mathbf{0} \\
\mathbf{C}_{\mathbf{q} i n} \ddot{\mathbf{q}}_{i n}+\mathbf{C}_{\mathbf{q} d p} \ddot{\mathbf{q}}_{d p}=\boldsymbol{\gamma}
\end{array}\right.
$$

式(26)の第 2 式，第 3 式よりそれぞれ式(27), (28)が得られる.

$$
\begin{aligned}
& \lambda=\mathbf{C}_{\mathbf{q} d p}{ }^{-T}\left(\mathbf{Q}_{d p}-\mathbf{M}_{d i} \ddot{\mathbf{q}}_{i n}-\mathbf{M}_{d p} \ddot{\mathbf{q}}_{d p}\right) \\
& \ddot{\mathbf{q}}_{d p}=\mathbf{C}_{\mathbf{q} d p}{ }^{-1}\left(\boldsymbol{\gamma}-\mathbf{C}_{\mathbf{q} i n} \ddot{\mathbf{q}}_{i n}\right)
\end{aligned}
$$

さらに，式(27)および式(28)を式(26)の第 1 式に代入することで次式のようにニュートン・オイラー方程式が得ら れる. 


$$
\widehat{\mathbf{M}}_{i n} \ddot{\mathbf{q}}_{i n}=\widehat{\mathbf{Q}}_{i n}
$$

ただし， $\widehat{\mathbf{M}}_{i n}, \widehat{\mathbf{Q}}_{\text {in }}$ は以下の通りである.

$$
\begin{aligned}
& \widehat{\mathbf{M}}_{i n}=\mathbf{B}^{\mathrm{T}} \overline{\mathbf{M}} \mathbf{B} \\
& \widehat{\mathbf{Q}}_{i n}=\mathbf{B}^{\mathrm{T}} \mathbf{T}_{i d}{ }^{\mathrm{T}} \mathbf{Q}-\left(\mathbf{M}_{i d}-\mathbf{C}_{\mathbf{q} i n}{ }^{\mathrm{T}} \mathbf{C}_{\mathbf{q} d p}{ }^{-\mathrm{T}} \mathbf{M}_{d p}\right) \mathbf{C}_{\mathbf{q} d p}{ }^{-1} \boldsymbol{\gamma} \\
& \left.\mathbf{B}=\left[\stackrel{[\mathbf{I}}{-\mathbf{C}_{\mathbf{q} d p}{ }^{-1} \mathbf{C}_{\mathbf{q} i n}}\right]\right]
\end{aligned}
$$

\section{3. 制御系設計}

本研究における制御目的はケーブルの先端に接続された機械システムの位置および姿勢を目標位置および目標 姿勢に安定化させることである。ここで, 制御系設計のために式(29)を成分表示すると式(33)のように表される.

$$
\left[\begin{array}{ll}
\mathbf{M}_{c c} & \mathbf{M}_{c r} \\
\mathbf{M}_{r c} & \mathbf{M}_{r r}
\end{array}\right]\left[\begin{array}{l}
\ddot{\mathbf{q}}_{c} \\
\ddot{\mathbf{q}}_{r}
\end{array}\right]=\left[\begin{array}{c}
\widetilde{\mathbf{Q}}_{\mathrm{c}} \\
\mathbf{Q}_{r}+\mathbf{Q}_{u}+\mathbf{Q}_{c c}
\end{array}\right]
$$

ただし， $\mathbf{q}_{c}$ および $\mathbf{q}_{r}$ はケーブルおよび岡体に関する独立な一般化座標べクトルであり， $\mathbf{M}_{c c}, \mathbf{M}_{c r}, \mathbf{M}_{r c}$ および $\mathbf{M}_{r r}$ は, $\mathbf{q}_{c}$ および $\mathbf{q}_{r}$ のそれぞれの次元に対応させた慣性行列のブロック行列であり， $\mathbf{M}_{r c}=\mathbf{M}_{c r}^{\mathrm{T}}$ である. また, $\widetilde{\mathbf{Q}}_{c}$ は 式(31)で表されるベクトル $\widehat{\mathbf{Q}}_{i n}$ のケーブルの座標に対応した成分であり， $\mathbf{Q}_{c c}$ は遠心・コリオリカに起因する項で ある.ここで, ANCF による定式化の特徵に着目すると慣性行列を構成するブロック行列は定数行列となるため, 式(33)に座標変換を適用することで, 式(34)のように表すことができる.

$$
\left[\begin{array}{cc}
\mathbf{M}_{c c} & \mathbf{0} \\
\mathbf{0} & \mathbf{M}_{r r}-\widehat{\mathbf{M}}
\end{array}\right]\left[\begin{array}{c}
\ddot{\mathbf{q}}_{c}+\ddot{\overrightarrow{\mathbf{q}}} \\
\ddot{\mathbf{q}}_{r}
\end{array}\right]=\left[\begin{array}{c}
\widetilde{\mathbf{Q}}_{\mathrm{c}} \\
\widehat{\mathbf{Q}}+\mathbf{Q}_{r}+\mathbf{Q}_{u}+\mathbf{Q}_{c c}
\end{array}\right]
$$

ただし， $\widehat{\mathbf{M}}, \widehat{\mathbf{q}}, \widehat{\mathbf{Q}}$ は以下のように表される.

$$
\begin{gathered}
\widehat{\mathbf{M}}=\mathbf{M}_{r c} \mathbf{M}_{c c}{ }^{-1} \mathbf{M}_{c r} \\
\ddot{\widehat{\mathbf{q}}}=\mathbf{M}_{c c}{ }^{-1} \mathbf{M}_{c r} \ddot{\mathbf{q}}_{r} \\
\widehat{\mathbf{Q}}=-\mathbf{M}_{r c} \mathbf{M}_{c c}{ }^{-1} \widetilde{\mathbf{Q}}_{\mathrm{c}}
\end{gathered}
$$

このとき，式(34)における第 2 ブロック行である剛体の一般化座標ベクトルに関する方程式を抽出すると，式(36) のように表される.

$$
\left(\mathbf{M}_{r r}-\widehat{\mathbf{M}}\right) \ddot{\mathbf{q}}_{r}=\widehat{\mathbf{Q}}+\mathbf{Q}_{r}+\mathbf{Q}_{u}+\mathbf{Q}_{c c}
$$

ここで，式(15)より剛体の質量が既知であれば $\mathbf{Q}_{r}$ を計算することが可能である．また，式(21)および式(35)の第 3

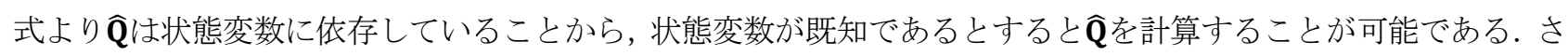
らに, 剛体の角度, 角速度を既知であるとすると, $\mathbf{Q}_{c c}$ を計算することが可能である. ここで, 制御入力ベクトル $\mathbf{Q}_{u}$ を式(37)のように与える.

$$
\mathbf{Q}_{\mathrm{u}}=\overline{\mathbf{Q}}_{\mathrm{u}}-\widehat{\mathbf{Q}}-\mathbf{Q}_{\mathrm{r}}-\mathbf{Q}_{c c}
$$

ただし， $\overline{\mathbf{Q}}_{u}$ は新たに導入したベクトルである.さらに，式(37)を式(36)に代入すると，運動方程式は式(38)のよう に表される.

$$
\left(\mathbf{M}_{r r}-\widehat{\mathbf{M}}\right) \ddot{\mathbf{q}}_{r}=\overline{\mathbf{Q}}_{u}
$$

このとき，前述のように ANCF を用いた定式化の特徵より式(36)における慣性行列 $\mathbf{M}_{r r}-\widehat{\mathbf{M}}$ は一定となり， $\overline{\mathbf{Q}}_{u}$ を 新たな制御入力ベクトルと捉えると, 式(38)は制御入力が印加された剛体の運動方程式とみなすことができる.

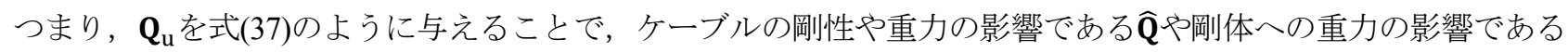
$\mathbf{Q}_{r}$ および遠心・コリオリカの影響である $\mathbf{Q}_{c c}$ を補償することができ，元の柔軟構造を含む機械システムの制御問 題は剛体の制御問題に変換されたことになる. したがって, 適切な制御入力ベクトル $\overline{\mathbf{Q}}_{u}$ をえることで, 剛体の 
位置および姿勢を正確に制御することが可能となる．本研究では制御入力ベクトル $\overline{\mathbf{Q}}_{u}$ として，式(39)に示すよう な PD 制御を導入する.

$$
\overline{\mathbf{Q}}_{u}=-\mathbf{K}_{p}\left(\mathbf{q}_{r}-\mathbf{q}_{r t}\right)-\mathbf{K}_{d} \dot{\mathbf{q}}_{r}
$$

ここで, $\mathbf{K}_{p}$ は比例ゲイン行列, $\mathbf{K}_{d}$ は微分ゲイン行列であり, 本研究では線形二次レギュレータにより最適ゲイン の計算を行う．また， $\mathbf{q}_{t t}$ は目標位置および目標姿勢を表すべクトルである.

ANCF ではない従来の有限要素法ではケーブルに関寸る慣性行列が変数に依存することから, 式(33)から式(34) への変換において必要となる慣性行列のブロック行列の逆行列の計算は, 各計算ステップごとに実施する必要が ある.また, 従来の有限要素法では, 式(37)で与えられるようなケーブルの挙動を補償するような制御則を導出し たとしても，より多くの要素数を導入することでケーブルの表現を正確に行う必要があり, ケーブルに関する慣 性行列の次元も大きくなる. その結果として, 前述のような逆行列の計算コストが非常に大きくなるため, 実装 の観点のみならず数值解析の観点からも現実的ではない. 一方, ANCF を用いることによって, ケーブルに関す る慣性行列は定数になることから, 式(33)から式(34)への変換において必要となる逆行列の計算は 1 度のみである 上に, ANCF では大変形を行う柔軟構造について従来の有限要素法に比べてより少ない要素で表現することがで きることから，ケーブルに関する慣性行列の次元も抑えることが可能である．また，従来の有限要素法による慣 性行列と ANCF による慣性行列が同じ次元であったとしても, 前者の場合には制御ループの各ステップごとに慣 性行列の逆行列を計算する必要があるものの, 後者の場合には制御ループに入る前の 1 度の計算で済むことから, 慣性行列の次元が大きくなるほどANCF を利用した本提案手法の計算性における効果が大きく現れる. そのため, 従来の有限要素法を用いた場合に比べ計算コストを非常に小さく抑えることが可能であり, 提案手法は実装の観 点のみならず数值解析の観点からも現実的な手法となっていることに注意されたい.

剛体部の座標変数に対する PID 制御のみによっても, ケーブルの影響をキャンセルすることで目標状態に収 束させることができると考えられるが, 対象が非線形システムであることから PID 制御器の適切なゲインを決 定するには試行錯誤的なプロセスなどが必要であり，効率的なゲイン決定は容易ではない，一方，提案手法では 剛体の制御問題に帰着させることができるため, 単純な剛体の PD 制御問題として制御系設計を行うことができ ることから，ゲインの決定は比較的容易である．そのような制御系設計の効率の点からも提案手法は有効である と考えられる.

\section{4. 状態推定}

3 章で提案した制御系設計手法における制御則の計算にはケーブルの状態変数が必要である. 実用的な観点よ り, 必要となるすべての状態変数を把握するためにケーブルに多数のセンサを取り付けることは困難である. し たがって, 状態変数を推定する必要がある. そこで本研究では, 剛体の位置と姿勢角を計測するセンサを取り付 けることができるものとし，センサの計測データから Unscented Kalman Filter（UKF）(Julier et al., 2000)によって ケーブルを含むシステムの状態変数を推定する．このとき，UKF を本制御対象に適用するために，式(33)から状 態方程式を求め, センサについての仮定から観測方程式を導出すると式(40)および式(41)のように表される.

$$
\begin{aligned}
& \frac{\mathrm{d}}{\mathrm{d} t}\left[\begin{array}{l}
\mathbf{q}_{\mathrm{c}} \\
\mathbf{q}_{\mathrm{r}} \\
\mathbf{q}_{\mathbf{c}} \\
\dot{\mathbf{q}}_{\mathrm{r}}
\end{array}\right]=\mathbf{A}\left[\begin{array}{l}
\mathbf{q}_{\mathbf{c}} \\
\mathbf{q}_{\mathbf{r}} \\
\dot{q}_{\mathbf{c}} \\
\mathbf{q}_{\mathbf{r}}
\end{array}\right]+\mathbf{B U} \\
& \mathbf{y}=\left[\begin{array}{llll}
\mathbf{0} & \mathbf{I} & \mathbf{0} & \mathbf{0}
\end{array}\right]\left[\begin{array}{l}
\mathbf{q}_{\mathbf{c}} \\
\mathbf{q}_{\mathbf{r}} \\
\dot{q}_{\mathbf{c}} \\
\dot{q}_{\mathbf{r}}
\end{array}\right]
\end{aligned}
$$

ただし，A，BおよびUは以下の通りである。

$$
\mathbf{A}=\left[\begin{array}{cc}
\mathbf{0} & \mathbf{I} \\
-\overline{\mathbf{M}}^{-1} \overline{\mathbf{K}} & \mathbf{0}
\end{array}\right], \quad \mathbf{B}=\left[\begin{array}{c}
\mathbf{0} \\
\overline{\mathbf{M}}^{-1}
\end{array}\right], \quad \mathbf{U}=\left[\begin{array}{c}
\widetilde{\mathbf{Q}}_{E c} \\
\mathbf{Q}_{r}+\mathbf{Q}_{u}+\mathbf{Q}_{c c}
\end{array}\right], \quad \overline{\mathbf{M}}=\left[\begin{array}{cc}
\mathbf{M}_{c c} & \mathbf{M}_{c r} \\
\mathbf{M}_{r c} & \mathbf{M}_{r r}
\end{array}\right], \quad \overline{\mathbf{K}}=\left[\begin{array}{cc}
\widetilde{\mathbf{K}}_{1}+\widetilde{\mathbf{K}}_{\mathbf{t}} & \mathbf{0} \\
\mathbf{0} & \mathbf{0}
\end{array}\right]
$$


また $\widetilde{\mathbf{Q}}_{E c}, \widetilde{\mathbf{K}}_{\mathbf{l}}$ および $\widetilde{\mathbf{K}}_{\mathbf{t}}$ は, 式(26)から独立座標のみに関する運動方程式である式(29)を抽出する際の変換において, $\mathbf{Q}_{E c}, \mathbf{K}_{\mathbf{l}}$ および $\mathbf{K}_{\mathbf{l}}$ に起因して導出されるものである.ここで, 図 3 に UKF による状態推定のブロック線図を示す. 本研究では, 式(44)によって得られた状態推定值 $\widehat{\mathbf{q}}(k)$ を用いて式(21)および式(35)で表される の值を用いて式(37)で表される $\mathbf{Q}_{u}$ を算出し, 制御入力として制御対象一与える. また, 以下に一般的な方法(足立, 丸田，2012)を本研究に適用した場合の UKF の計算手順を簡易的に示寸. 状態推定值 $\widehat{\mathbf{q}}(0)$ および共分散行列 $\boldsymbol{P}(0)$ の初期值を設定し，各ステップ $k=1,2, \cdots, n$ に対して計算を行う.

1) 1 ステップ前に得られた状態推定值 $\mathbf{q}(k-1)$ および共分散行列 $\boldsymbol{P}(k-1)$ からシグマポイントを計算する.

2) 計算したシグマポイントから事前状態推定値 $\widehat{\mathbf{q}}^{-}(k)$ および事前誤差共分散行列 $\boldsymbol{P}^{-}(k)$ を計算する.

3) 事前状態推定值 $\widehat{\mathbf{q}}^{-}(k)$ および事前誤差共分散行列 $\boldsymbol{P}^{-}(k)$ からシグマポイントを再計算する.

4) 出力シグマポイントから事前出力推定值 $\hat{\mathbf{y}}^{-}(k)$ を計算する.

5) 事前観測推定值 $\hat{\mathbf{y}}^{-}(k)$ から事前出力誤差共分散行列 $\boldsymbol{P}_{y y}^{-}(k)$ および事前状態・出力誤差共分散行列 $\boldsymbol{P}_{x y}^{-}(k)$ を計 算する.

6) 事前出力誤差共分散行列 $\boldsymbol{P}_{y y}^{-}(k)$, 事前状態・出力誤差共分散行列 $\boldsymbol{P}_{x y}^{-}(k)$ および観測誤差の分散 $\sigma_{w}^{2}$ から式(43) を用いてカルマンゲイン $g(k)$ を計算する.

$$
g(k)=\frac{\boldsymbol{P}_{x y}^{-}(k)}{\boldsymbol{P}_{y y}^{-}(k)+\sigma_{w}^{2}}
$$

7）前述した值から式(44)および(45)を用いて状態推定值 $\mathbf{q}(k)$ および共分散行列 $\boldsymbol{P}(k)$ を計算する．以上の手順 を繰り返すことにより各ステップにおける状態推定を行う。

$$
\begin{aligned}
& \widehat{\mathbf{q}}(k)=\widehat{\mathbf{q}}^{-}(k)+g(k)\left\{\mathbf{y}(k)-\hat{\mathbf{y}}^{-}(k)\right\} \\
& \boldsymbol{P}(k)=\boldsymbol{P}^{-}(k)-g(k)\left(\boldsymbol{P}_{x y}^{-}(k)\right)^{T}
\end{aligned}
$$

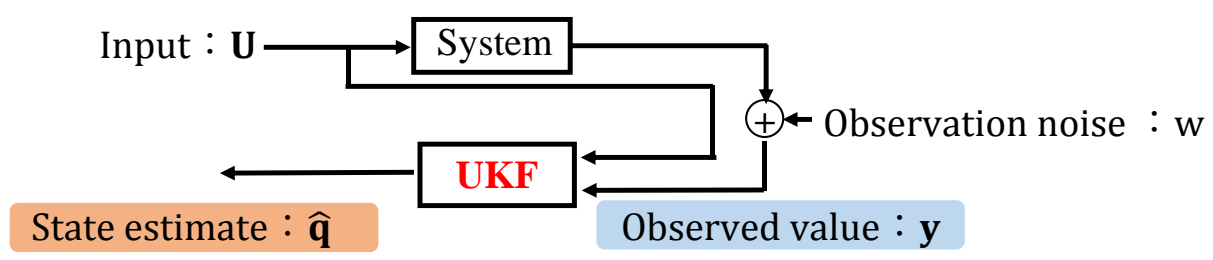

Fig. 3 By adding observation value and input to UKF, the state estimate value is obtained.

\section{5. 提案した制御系の数值解析による有效性の検証}

4 章で導入した状態推定を 3 章の提案した制御系に適用し，数值解析を行う.ケーブルがたるんだ状態（張力 が発生しない状態）を初期状態とし，剛体を目標位置および目標姿勢に制御することを制御目的とする．また， 提案手法を適用する対象である数值解析のモデルは T1-L2 モデルに基づいて導出した式(18)を用いる.

表 1 に数值解析に用いたパラメータを示す. 図 4 には時刻歴における初期状態である $0.0 \mathrm{~s}$ から収束した状態で ある $5.0 \mathrm{~s}$ までの $1.0 \mathrm{~s}$ ごとのケーブルおよび岡体の状態を示し, 図 5 には時刻歴における $0.6 \mathrm{~s}$ から $1.2 \mathrm{~s}$ までの $0.3 \mathrm{~s}$ ごとのケーブルおよび岡体の状態を示す.ここで, 赤線および青点がそれぞれケーブルおよび岡体である. 図 6 , 図 7 および図 8 にはそれぞれ剛体の $x, y$ および $\theta$ の時刻歴応答を示す. 橙点線は目標位置, 青実線はケーブルの 影響を考慮せずに剛体のみについての制御系を適用した場合（以下「剛体のみの制御系」）の位置および姿勢, 赤 実線はケーブルに関する全状態量が既知であるというもとで提案する制御系を適用した場合（以下「既知の状態 量を用いた提案手法」）の位置および姿勢, 緑実線は提案する制御系にUKFによって推定された状態量を適用し た場合（以下「推定した状態量を用いた提案手法」）の位置および姿勢である.

図 4, 図 6, 図 7 および図 8 からすべての場合において $x, y$ および $\theta$ は目標位置および目標姿勢に収束してい ることが分かる. 剛体のみの制御系と既知の状態量を用いた提案手法を比較すると, 既知の状態量を用いた提案 手法の方が応答性が良く，また高い精度で目標位置および目標角度に収束していることが分かる．これは既知の 
状態量を用いた提案手法では，式(37)で示したような状態量を用いた計算によってケーブルの影響が補償される ことで，ケーブルの影響を受けることなく剛体が式(39)の PD フィードバック制御によって制御されたためであ ると考えられる. また, 本研究では目標值が一定值の PD フィードバック制御であることから, 初期状態におけ る目標值との大きな偏差に起因した大きな力およびトルクが発生し，ケーブルに大きな加速度が発生する．その 結果として, 図 5 に示すように制御開始直後にケーブルは大きく変形しケーブルそのものに振動が発生している ものの，提案手法ではそのようなケーブルの動的な影響をキャンセルすることで, 剛体を目標状態に収束させる ことができている．これらの結果から，提案した手法は有効であると考えられる．また，既知の状態量を用いた 提案手法と推定した状態量を用いた提案手法を比較すると，推定した状態量を用いた提案手法ではわずかな偏差 が残り，振動的な挙動を示していることが分かる．これは，推定した状態量を用いた提案手法では推定のために 用いたモデルは線形化したモデルであることや状態推定精度の関係より, 状態量と真值の間に誤差が発生するた め，その結果としてケーブルの影響を完全に打ち消せていないためであると考えられる．また，そのようなモデ ル化誤差などを要因とする推定精度の悪化により，システムが不安定化する可能性もあることから，実装を考慮 する際には推定精度の十分な評価が必要であると考えられる．ケーブルの状態推定精度を上げ，制御性能を向上 させる必要性があるものの, UKFによって推定した状態量を用いた場合の提案手法においてもその有效性を確認 することができる.

Table 1 Parameter of numerical analysis.

\begin{tabular}{|l||c|}
\hline Number of elements $N$ & 10 \\
\hline Gravitational Acceleration $g$ & $9.81 \mathrm{~m} / \mathrm{s}^{2}$ \\
\hline Length of cable $L_{c}$ & $3 \mathrm{~m}$ \\
\hline Cross-sectional area of cable $A_{c}$ & $0.005 \times 0.005 \mathrm{~m}^{2}$ \\
\hline Density of cable $\rho_{c}$ & $1000 \mathrm{~kg} / \mathrm{m}^{3}$ \\
\hline Young's modulus of cable $E_{c}$ & $1.0 \times 10^{7} \mathrm{~Pa}$ \\
\hline Volume of Rigid body $V_{r}$ & $0.05 \times 0.05 \times 0.05 \mathrm{~m}^{3}$ \\
\hline Density of Rigid body $\rho_{r}$ & $7870 \mathrm{~kg} / \mathrm{m}^{3}$ \\
\hline
\end{tabular}

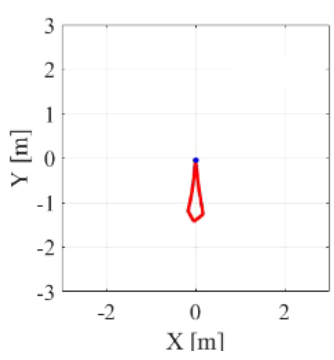

(a) $t=0.0 \mathrm{~s}$

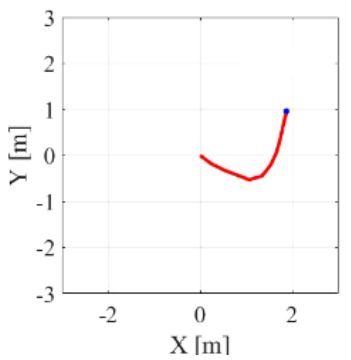

(d) $t=3.0 \mathrm{~s}$

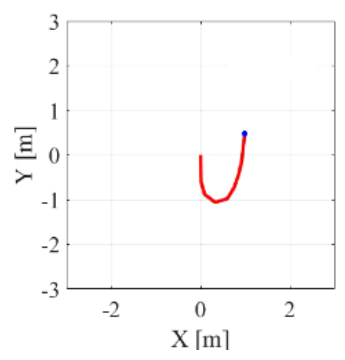

(b) $t=1.0 \mathrm{~s}$

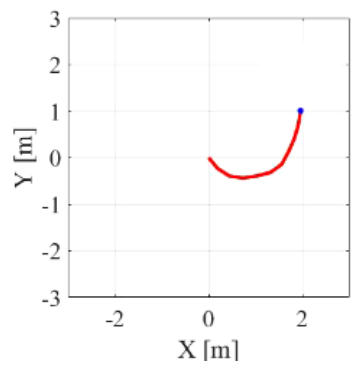

(e) $t=4.0 \mathrm{~s}$

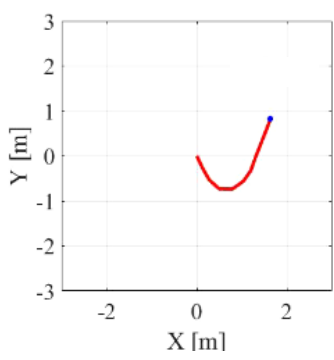

(c) $t=2.0 \mathrm{~s}$

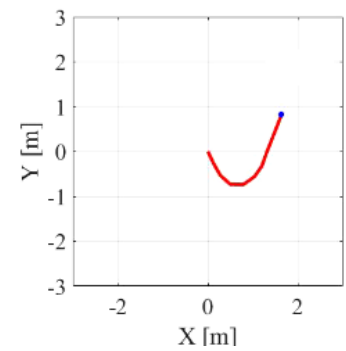

(f) $t=5.0 \mathrm{~s}$

Fig. 4 Cables and rigid bodies are depicted in each 1.0s from 0.0s to 5.0s. These figures show that cable and rigid body are relatively well controlled. 


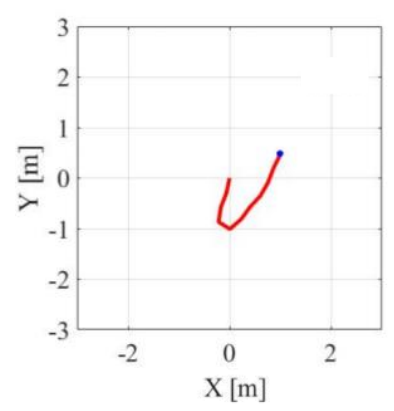

(a) $t=0.6 \mathrm{~s}$

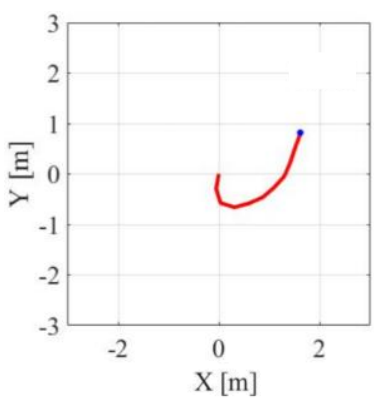

(b) $t=0.9 \mathrm{~s}$

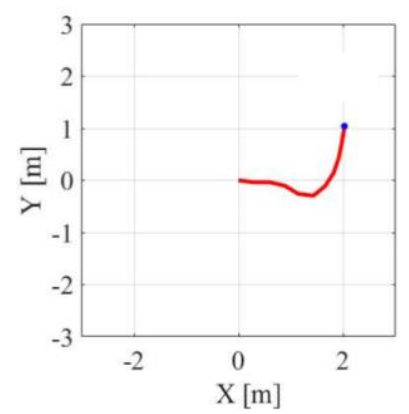

(c) $t=1.2 \mathrm{~s}$

Fig. 5 Cables and rigid bodies are depicted in each $0.3 \mathrm{~s}$ from $0.6 \mathrm{~s}$ to $1.2 \mathrm{~s}$. These figures show that the cable is largely deformed.

\section{6. まとめと今後の課題}

\section{$6 \cdot 1$ まとめ}

ケーブルを有した機械システムのモデル化を行い，ANCF によって得られた数学モデルの特性を利用した制御 系設計法を提案した．また，提案手法ではケーブルの状態量の情報が必要であるが，実用的な観点から UKFによ ってケーブルの状態量を推定し，提案手法への適用を試みた．状態量が既知であるとした場合および UKF によ って推定した状態量を用いた場合の両方において, 提案手法が有効であることを数值解析によって示した. また, ANCF によって得られた数学モデルは慣性行列が定数であることから, ケーブルに対して従来の有限要素法を適 用した場合に比べて, 提案手法における計算負荷は非常に小さく，実用的な観点のみならず数值解析の観点から も優位性を有する.

\section{$6 \cdot 2$ 今後の課題}

緒言で挙げた例のようなケーブルが接続されたヘリコプタや海中ロボットにおいては，ケーブルに対し空気抵 抗や海水の抵抗などの外力が加わり，ケーブルが高速で運動を行うような場合については本提案手法での制御性 能は劣化する可能性がある，そのため，ケーブルに加わる様々な外力を考慮できるように提案手法を拡張する必 要がある．また，ケーブルには複数のモードの振動が発生するが，制御対象となる振動モードは一般的には低次 のモードである．より計算効率を上げるためにも制御系設計に用いるモデルを低次元化することが有効であると 考えられる. さらに, 実用性のためにも提案手法を 3 次元モデルに拡張寸ることが必要であり, さらに提案手法 の有効性を示すためにも実験検証が今後の課題である. 


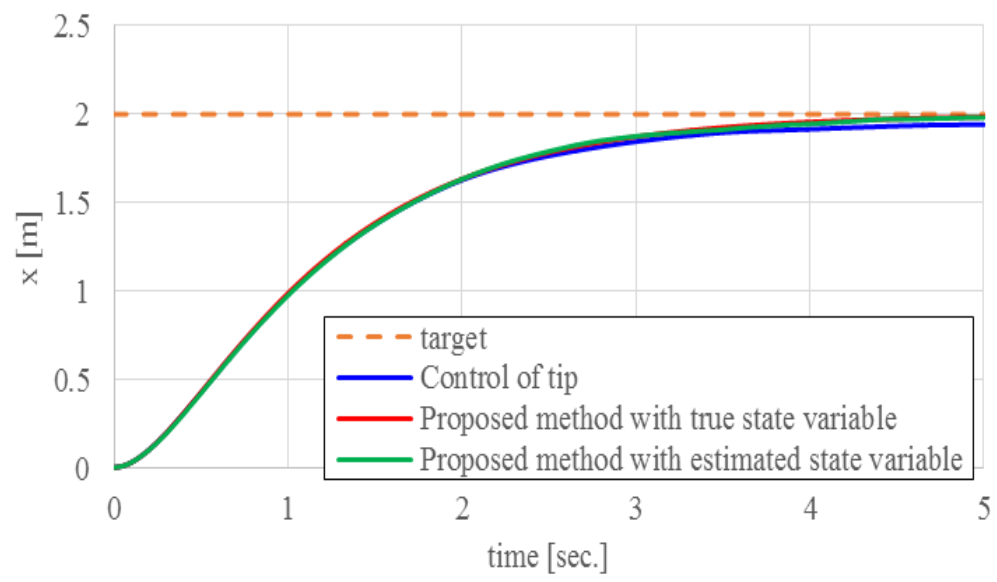

Fig. 6 Time history of the rigid body displacement in $x$ direction for different control method. Blue, red and green line show responses by simple feedback control of tip, proposed method with true state variable and proposed method with estimated state variable, respectively. Responses by the proposed methods with true and estimated variables show slightly better convergence to the target state compared to by the simple feedback control of tip.

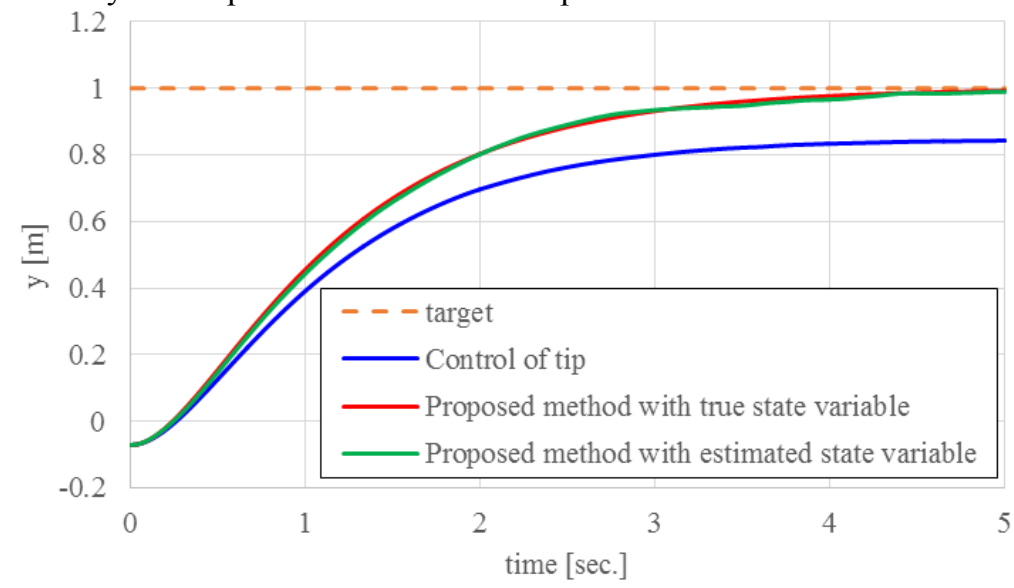

Fig. 7 Time history of the rigid body displacement in $y$ direction for different control method. Blue, red and green line show responses by simple feedback control of tip, proposed method with true state variable and proposed method with estimated state variable, respectively. Responses by the proposed methods with true and estimated variables show much better convergence to the target state compared to by the simple feedback control of tip.

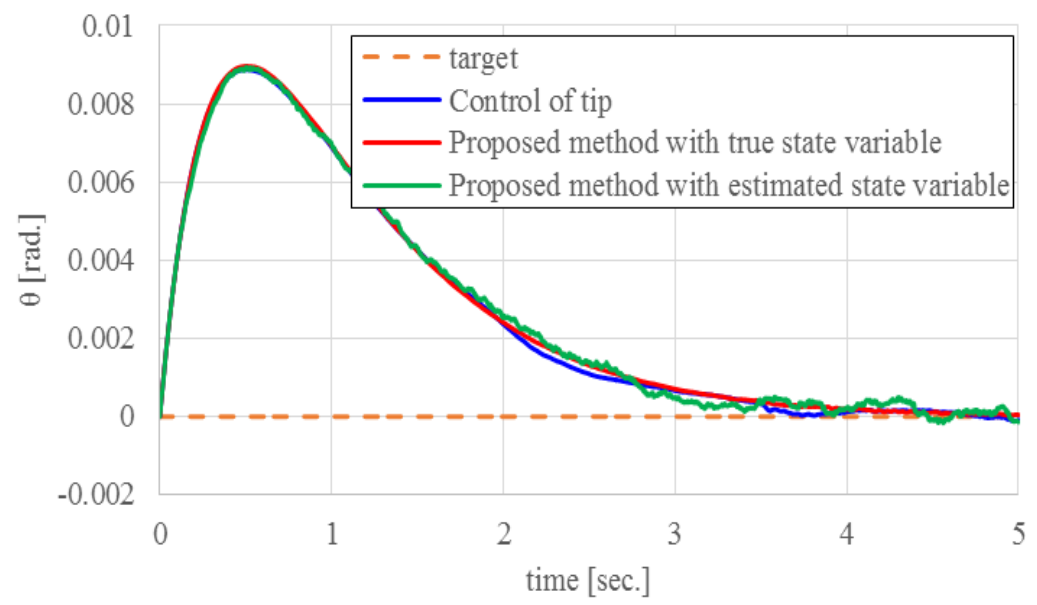

Fig. 8 Time history of the rigid body displacement in $\theta$ direction for different control method. Blue, red and green line show responses by simple feedback control of tip, proposed method with true state variable and proposed method with estimated state variable, respectively. Responses by three methods show convergence to the target state. The proposed method with estimated variable shows vibratory behavior around target state. 


\section{文献}

足立修一, 丸田一郎，カルマンフィルタの基礎，東京電機大学出版局 (2012), pp.152-191.

Berzeri, M. and Shabana, A. A., Development of simple models for the elastic forces in the absolute nodal coordinate formulation, Journal of Sound and Vibration, Vol.235, No.4(2000), pp.539-565.

今津篤志, 野口博貴, 川合忠雄, 地上局とケーブルでつながれたヘリコプターの制御に関する研究 一張力推定方 法と張力補償制御一, 計測自動制御学会論文集, Vol.50, No.12(2014), pp.821-828.

今津篤志, 野口博貴, 川合忠雄, 地上局とケーブルでつながれたヘリコプターシステムにおける最適なケーブル 長さに関する研究, 計測自動制御学会論文集, Vol.52, No.4(2016), pp.220-227.

Julier, S., Uhlmann, J. and Durrant-Whyter, H. F., A new method for nonlinear transformation of means and covariances in filters and estimates, IEEE Transaction on Automatic Control, Vol.45, No.3(2000), pp.477-482.

Shabana, A. A., Hussien, H. A. and Escalona, J. L., Application of the absolute nodal formulation to large rotation and large deformation problems, Journal of Mechanical Design, Vol. 120 (1998), pp.188-195.

菅原佳城，小林信之, ANCF 法に基づくモデルを利用した柔軟マルチボディシステムの制御系設計法（2 次元柔軟 梁の位置および振動制御の例），日本機械学会論文集 C編，Vol. 78, No. 789 (2012), pp. 1553-1564.

田所諭, 防災ロボットについて我が国が取り組むべき中長期課題, 日本ロボット学会誌, Vol.32, No.2(2014), pp.154161.

浦環, 海中に求められるロボット, 日本ロボット学会誌, Vol.22, No.6(2004), pp.692-696.

山川雄司, 並木明夫, 石川正俊, 高速ロボットアームを用いた柔軟紐の動的マニピュレーション, 日本ロボット学 会誌, Vol.31, No.6(2013), pp.628-638.

\section{References}

Adachi, S. and Maruta, I., Fundamentals of Kalman filter, Tokyo Denki University Press (2012), pp.152-191 (in Japanese).

Berzeri, M. and Shabana, A. A., Development of simple models for the elastic forces in the absolute nodal coordinate formulation, Journal of Sound and Vibration, Vol.235, No.4(2000), pp.539-565.

Imadu, A., Noguchi, H. and Kawai, T., Control of helicopters cabled to ground station: - Compensation of cable tension and the tension estimation method -, Transactions of the Society of Instrument and Control Engineers, Vol.50, No.12(2014), pp.821-828 (in Japanese).

Imadu, A., Noguchi, H. and Kawai, T., Optimum cable length for helicopter with cable to ground station, Transactions of the Society of Instrument and Control Engineers, Vol.52, No.4(2016), pp.220-227 (in Japanese).

Julier, S., Uhlmann, J. and Durrant-Whyter, H. F., A new method for nonlinear transformation of means and covariances in filters and estimates, IEEE Transaction on Automatic Control, Vol.45, No.3(2000), pp.477-482.

Shabana, A. A., Hussien, H. A. and Escalona, J. L., Application of the absolute nodal formulation to large rotation and large deformation problems, Journal of Mechanical Design, Vol. 120 (1998), pp.188-195.

Sugawara, Y. and Kobayashi, N., A controller design method for flexible multibody system expressed by ANCF (Location and vibration control of flexible beam) , Transactions of the Japan Society of Mechanical Engineers, Series C, Vol. 78, No. 789 (2012), pp. 1553-1564 (in Japanese).

Tadokoro, S., Middle-long term issues of disaster robots in Japan, Journal of the Robotics Society of Japan, Vol.32, No.2(2014), pp.154-161 (in Japanese).

Ura, T., Robots for underwater world, Journal of the Robotics Society of Japan, Vol.22, No.6(2004), pp.692-696 (in Japanese).

Yamakawa, Y., Namiki, A. and Ishikawa, M., Dynamic manipulation of a flexible rope using high-speed robot arm, Journal of the Robotics Society of Japan, Vol.31, No.6(2013), pp.628-638 (in Japanese). 